\title{
Natural Experiments in U.S. Broadband Regulation
}

\author{
THOMAS W. HAZLETT * \\ Director, Information Economy Project, George Mason University \\ ANIL CALISKAN \\ Information Economy Project, George Mason University
}

\begin{abstract}
Regulations governing broadband networks are being considered. Natural experiments conducted with respect to "open access" rules yield probative marketplace evidence. Using the metric of subscribership, policy regimes are compared. Prior to 1Q2003, cable modem service was unregulated (and has remained so), while digital subscriber lines (DSL) were subject to network unbundling mandates. Those rules were effectively lifted in 1Q2003 and 3Q2005. Across regimes, subscriber growth appears significantly and negatively correlated with regulation. By year-end 2006, DSL subscribership was about 65\% above the trend established in the regulated pre-1Q2003 era, a difference of eight to ten million households.
\end{abstract}

\section{Introduction}

A debate is taking place over the optimal economic structure of computer networks. Citing the dominance of two rival broadband networks in residential markets, net neutrality (NN) advocates argue that Internet Service Providers (ISPs) will exploit "gatekeeper” positions to decrease competition in complementary markets, punishing consumers. These broadband networks are seen to be in a position to extract rents from customers or content suppliers by blocking (and unblocking) the flow of e-commerce, a variant of the vertical foreclosure argument (Farrell and Weiser, 2003and Economides, 2007). ${ }^{1}$

Some see the problem as best dealt with via existing antitrust policies (Kahn, 2007 and Neuchterlein, 2008), while others advance new remedies. Rules are proposed ${ }^{2}$ to prevent broadband ISPs from preferentially supplying improved access to particular applications (particularly those owned by, or paying, the ISP). Whatever the merits of these policies, such limits carry costs. The reduced flexibility afforded consumers, ISPs, caching services, and content providers in contracting for services constrains the range of business models over which markets may optimize.

\footnotetext{
* Contact author: Thomas W. Hazlett. Professor of Law \& Economics, Director of the Information Economy Project, George Mason University. E-mail: thazlett@gmu.edu The authors wish to thank Kathryn Zeiler, Howard Shelanski, Dennis Weisman, Timothy Tardiff, seminar participants at Georgetown Law Center and an anonymous referee for useful comments. The authors, of course, remain fully liable for any errors or omissions.

${ }^{1}$ For an elaboration on the argument for NN regulation, see $\mathrm{Wu}$ (2003).

${ }^{2}$ It is not clear precisely what NN rules would be imposed (Peha, 2007).
} 
The costs of regulation are substantial if the benefits of vertical integration are large. Such integration is commonly observed in the development of communications networks (Owen, 2007 and Hahn and Litan, 2007). Importantly, scale efficiencies may be at risk even in situations where the policy intervention does not force vertical disintegration (by imposing structural separation). By permitting rivals to gain access to network assets at regulated rates, the network owner may face greater difficulty in capturing economic returns from investments. Capital expenditures, including outlays to improve physical infrastructure and to induce customer adoption of a new technology, are shared with third party providers on terms set by government, inviting possible free riding by non-investors. In any event, constraining ISPs shrinks the range of profit-maximizing options, reducing incentives for creating and expanding broadband networks. This forms the crux of the argument against mandated NN (Hahn and Wallsten, 2006).

These direct effects may be offset in part or in whole by indirect effects that encourage innovation in applications and thereby increase demand for Internet access. Where the increase is sufficient in scale to dominate the costs of regulation, ISPs will face stronger incentives to invest in network capacity, despite being constrained from achieving a local profit maximum.

This rationale is provided in the "end to end" argument supplied by Lessig and Lemley (2000), Wu (2003) and others. Their view posits that transactional and organizational efficiencies result from separating ownership of basic transport functions (via physical networks connecting backbones and ISPs) from content. Specifically, removing ISP control over applications facilitates competitive entry into creation of the latter. By removing the prospect of vertical integration (by ownership or contract), traffic is said to flow freely "end-to-end", stimulating innovation "at the edge". This view is disputed in its portrayal of Internet architecture (Yoo, 2004).

Whatever differences exist in this lively discussion, there is a fundamental consensus that the gulf between policy positions needs to be bridged with empirical evidence. The ostensible purpose of $\mathrm{NN}$ rules is to increase efficiency and promote conditions that improve the products consumers use. Such rules entail trade-offs, however, that may entirely offset intended effects, reducing consumer welfare. Simply stated, incentives for network investment decline when network owners lose a set of valuable property rights, as in the case where regulation is imposed to block certain pricing or bundling models. Whether a corresponding intensification of demand via edge product stimulation occurs remains a fact question.

Lawrence Lessig articulates this point in presenting the case for net neutrality regulation. In 2006, he characterized the argument that such rules "would burden investment" a "fallacy", and wedged this verdict on observed marketplace outcomes. "Of course, this is an empirical claim." 3 The source for Lessig's conclusion was attributed to Gerald Faulhaber (2002), which evaluated the impact of "open access" regulation for deployment of broadband services. Such rules, similar to NN policies, mandate that a broadband network permit rivals to lease its facilities in order to supply competitive retail service. Open access can be applied both to cable modem (CM) access and to digital subscriber line (DSL) service provided over telephone networks. In the latter instance, where it has been implemented in the U.S., it can also involve "line sharing", where entrants are permitted to send high-speed data over local loops simultaneously used to make voice phone calls over standard (circuit switched) technology.

\footnotetext{
${ }^{3}$ Lawrence Lessig (2006) Presentation at the Event “Key Issues in Telecommunications Policy” organized by AEI-Brookings Joint Center for Regulatory Studies on May 10, 2006, available at http://www.aeibrookings.org/events/page.php?id=155
} 
Like NN rules, "open access" has been offered as a policy protecting "end to end" data flows (Lemley and Lessig, 2000), eliminating gatekeepers by yielding subscribers and application vendors a choice of alternative ISPs. Hence, in arguing for NN, Lessig offered Faulhaber's conclusion as empirical justification:

[I]t is difficult to sustain the argument that regulatory policy regarding open access for cable or line sharing for digital [subscriber line] service has in any way been an impediment to broadband deployment. If there have been impediments, to deployment, they have been overwhelmingly on the supply side (Faulhaber 2002, p.241).

The more telling component of this analysis, however, specified the conclusion and contained a crucial caveat. Given that cable TV operators were then, as now, unregulated (that is, not subject to open access mandates), Faulhaber focused on the effect of open access on DSL carriers, primarily incumbent local exchange carriers (ILECs), of which the largest are the Bell companies. He wrote:

[T] he regional Bells are deploying broadband as fast as they can as a competitive necessity, and they have been willing to suffer substantial internal inefficiencies to do so. It is likely that the cost increase due to the line-sharing mandate is small compared to these other costs and will have no effect on the deployment speed of digital subscriber lines. Ultimately, this is an empirical issue, and the hard evidence of what these costs are and how they compare to the relevant market incentives is not yet available (Ibid.).

This interpretation motivates further empirical analysis. Since Faulhaber's conclusion was offered, more systematic deployment data have become available. ${ }^{4}$ An international comparison of broadband regulatory regimes in the European Union has thus found that more "generous" access regulation deters investment in telecom infrastructure (Waverman et al, 2007). In the U.S., meanwhile, two fundamental policy regime switches occurred in 2003 and 2005, both with key implications for residential broadband access suppliers. While NN has not specifically been imposed, open access regulations have, carrying similar implications for consumers and producers. We examine those shifts herein.

$\mathrm{NN}$ and open access are close policy substitutes, ${ }^{5}$ and the market's reaction to open access serves as a proxy for the likely effects of NN. This logic flows directly from Lawrence Lessig's use of Faulhaber's conclusion, gleaned from implementation of open access obligations on telephone carriers offering DSL, as factual support for the position that NN will not deter broadband deployment.

Hence, open access regulation in U.S. broadband markets offer a potentially useful natural experiment. Testing the deployment effects of regulatory changes already occurring in broadband markets yields evidence on the likely effects of NN mandates. Given that the policy debate hinges on empirical verification, these data should prove crucial to the policy debate ongoing.

Of added significance to this study is the fact that the open access regime originally applied to DSL networks relied upon "line sharing”, wherein voice circuits supplied by the incumbent telephone carrier were (and still are) simultaneously used to provide high-speed data service. ${ }^{6}$ Given the sunk nature of the infrastructure supplying this capacity, Prof.

\footnotetext{
${ }^{4}$ Interestingly, Faulhaber has also rendered an empirical assessment that a related regulatory policy for voice (narrowband) services, unbundling local loops, was ineffective in advancing local telephone competition (Faulhaber, 2003).

${ }^{5}$ It is acknowledged that they are not perfect policy substitutes, in that the open access approach imposes regulation at the transport level, with NN imposed at the content (or content access) level.

${ }^{6}$ This extra capacity is made possible by the fact that the high-frequency portion of the local loop is wellsuited for data transport, but is unused for voice traffic. Hence, the "last mile" links that take DSL traffic from phone company central offices (where digital switches route data bits to the Internet) to end users and back, used vacant spectrum spaces in conduits largely constructed prior to any
} 
Alfred Kahn found the economic logic of regulated, low-priced access obligations levied on telephone networks relatively compelling (Kahn, 2003, pp.43-45). The sunk cost logic is, however, incomplete. As Kahn allowed, efficient investment incentives may be disrupted by regulated open access. An empirical test of the impact of DSL deregulation, where incumbents enjoy "close-to-zero marginal cost" in the network capacity appropriated, then constitutes a strong test, under highly favorable conditions, of the thesis that broadband regulation can be used to advance consumer interests.

\section{Broadband regulation}

\subsection{General approach}

Rules were initially imposed on telephone company-delivered digital subscriber line (DSL) services, and then largely removed by regulators. Residential broadband markets then offer a test bed for the effectiveness of open access policies, one that incorporates the potential market power of broadband internet service providers (ISPs). To the degree that existing providers inefficiently restrict consumers' choices, regulatory constraints more easily improve outcomes.

This inquiry focuses on the broadband deployment as proxied by CM and DSL residential subscribership. This is the general approach suggested by Faulhaber (2002) and elsewhere. Residential subscribership is a simple, highly-aggregated metric, signaling an outcome of key interest to policy makers. While examining the effects of regulation on DSL growth, general broadband trends in the U.S. and technological developments that potentially affect DSL subscribership are proxied by U.S. CM and Canadian DSL and CM subscribership. A number of alternative specifications are used to test the general hypothesis that broadband regulation (as in open access rules) increases efficiency. ${ }^{7}$

\subsection{Three regimes for regulating DSL}

Three identifiable regulatory regimes have governed DSL. As CM service has been consistently unregulated (no open access mandates) from inception in the mid-1990s, the episodic variation of DSL regulation enables empirical analysis comparing DSL v. CM outcomes.

\subsubsection{Regime I: Regulated DSL with line sharing obligations (pre-2003)}

Cable TV operators began offering CM services in 1995 (Rosston, 2006, p.6) without any obligation to share network infrastructure with rival service providers. A cable system operator such as TCI or AT\&T (which purchased TCI in 1997) could offer broadband Internet access to retail customers via vertical integration, or via an exclusive contract with an ISP such as @Home. Alternatively, an independent ISP such as Earthlink could negotiate an agreement to sell Internet access to retail customers using the cable operator's network, but such deals were unregulated.

A campaign requesting mandatory wholesale access, at reasonable terms and conditions, quickly materialized, led by America Online (AOL) and GTE (a large local telephone carrier later acquired by Verizon) (Esbin, 1998 and 2000). These efforts were

\footnotetext{
${ }^{7}$ Historical data on broadband service pricing are difficult if not impossible to obtain; hence, the analysis to follow does not differentiate between regulatory regimes based on price levels, but on categorical regulatory distinctions.
} 
unsuccessful. ${ }^{8}$ A 1999 FCC report concluded that access regulation would risk deterring investment in the rapidly evolving market (FCC, 1999). The FCC later classified CM access as an interstate information service, categorically exempting it from commoncarrier or open access obligations at the federal, state, or local level. The U.S. Supreme Court upheld the FCC's determination in June 2005 (Brand X, 2005).

In contrast to unregulated CM services, DSL services were regulated from their inception in the mid-1990s. In particular, incumbent local exchange carriers (ILECs) supplying DSL faced three major obligations. First, under the Computer III regime, telephone companies were required to provide the broadband transmission component of DSL services on a common-carrier basis (FCC, 2005, pp.19-20). Second, under the Commission's unbundling rules, telephone companies were mandated to provide the copper loops used to provide DSL service on an unbundled basis. ${ }^{9}$ This enabled competitive local exchange carriers (CLECs, or dCLECs for those entrants specializing in data services) to place their switches in a telephone company's central office and to connect that equipment to an unbundled loop supplying DSL services to end users. Third, the FCC's "line sharing" rules required telephone companies to lease just the highfrequency portion of the loop ("HFPL") used to provide DSL services (FCC, 1999). Federal and state regulations then set the price for the HFPL far below the price for an unbundled loop as a whole, substantially reducing dCLEC costs. ${ }^{10}$

\subsubsection{Regime II: DSL partially deregulated (ex-line sharing)}

In February 2003, the FCC eliminated DSL line sharing rules. ${ }^{11}$ This meant that, in order to supply DSL service to customers over an ILEC's lines, dCLECs would have to pay for the entire local loop or strike a commercial agreement with the carrier to share a loop. The rationale for the reform was that, with lessened network sharing obligations, telephone carriers would invest more heavily in bringing broadband services to residential customers (Crandall, 2005, p.127).

FCC member (later Chairman) Kevin Martin voted for the measure, noting "that competition - not regulation - is the best method of delivering the benefits of choice, innovation and affordability to consumers". ${ }^{12}$ The policy switch was criticized by others, however, as a measure that would unleash market power, slowing broadband deployment. "For consumers, it's a bleak day, according to the Consumer Federation of America. There are about 40 million DSL subscribers now in the United States, and today's decision will likely choke off any future growth, one consumer group said." 13

Hence, a natural experiment was created. As developments in the residential broadband markets have played out, subscriber growth trends across the regime switches can now be observed, shedding light the potential effects of regulation.

\footnotetext{
${ }^{8}$ The AOL/Time Warner merger, consummated in early 2000, imposed unique third party access obligations. The provisions required the merged firm to offer AOL Broadband only after permitting two independent ISPs to utilize Time Warner Cable infrastructure. The rules did not regulate wholesale prices, nor did they regulate Time Warner's Road Runner broadband ISP.

${ }^{9} 47$ C.F.R. $\S 51.319(\mathrm{a})(1)$.

${ }^{10} 47$ C.F.R. $\S 51.319(\mathrm{a})(1)(\mathrm{i})$.

${ }^{11}$ FCC (2003) News distributed on February 20, 2003 in CC Docket 01-338: FCC Adopts News Rules for Network Unbundling Obligations Of Incumbent Local Phone Carriers, February 20, http://hraunfoss.fcc.gov/edocs_public/attachmatch/DOC-231344A1.pdf

${ }^{12}$ Ben Charny (2003) “FCC Loosens Broadband Rules,” CNET NEWS.com, February 20, http://news.com.com/FCC+loosens+broadband+rules/2100-1033_3-985313.html

${ }^{13}$ Ibid. The CFA attributed the slowdown in growth to "higher prices and fewer choices for consumers in high-speed services."
} 


\subsubsection{Regime III: Unregulated cable/unregulated DSL}

In August 2005, the FCC eliminated the Computer III rules with respect to DSL services. This removed the remaining open access regulations when Internet connections are bundled with transport. With the Commission determining that DSL fell under Title I of the Communications Act, broadband Internet access became treated as an "information service" exempt from common-carrier regulation. ${ }^{14}$ This essentially put broadband DSL services on regulatory parity with CM service. ${ }^{15}$ The rationale, as with the line-sharing deregulation, was that reducing network sharing mandates would improve operator incentives to deploy, upgrade, and market broadband access. Once again, proponents of regulation argued that the FCC's deregulatory steps would have negative consequences for broadband customers and the Internet generally. ${ }^{16}$

\section{Empirical outcomes}

The thrust of open access rules is to allow competitive ISPs to employ cable modem (CM) and/or digital subscriber line (DSL) networks. Via such independent, non-integrated ISPs, end users may obtain unfettered access to Internet content and applications, as ISPs unaffiliated with the underlying broadband network have no business interest in inefficient blocking. This not only parallels the theoretical argument for Net Neutrality (NN), it operates as a similar policy intervention, setting regulatory terms for broadband service providers by mandating user access to vertical services. In either case, common carrier regulation supersedes market forces (Owen, 2007).

Indeed, in the policy debate open access and $\mathrm{NN}$ are portrayed as substitutes. Advocates for NN frequently base their argument for regulation on the elimination of DSL's open access regime. For instance, THE NEW REPUBLIC editorialized for NN legislation in June 2006 on the grounds that, during the previous year, the FCC "exempted telecoms that provide Internet connections from [open-access] restrictions, dealing a blow to both entrepreneurship and political discourse". ${ }^{17}$ Similarly, Vinton Cerf, co-developer of the IP/TCP protocol and "Chief Technology Evangelist" for Google, recommends implementation of NN due to elimination of open access. "Cerf said that he thought things were better before 2005 when broadband providers were controlled by common carriage rules that prevented providers from discriminating in terms of what traffic was carried. 'It protected the Internet,' he said."18

The parallel nature of these policy approaches allows empirical evaluation of NN prior to its adoption. Herein, we examine how broadband subscribership responds to changes in broadband regulations, testing the implications of open access rules on the evidence

\footnotetext{
${ }^{14}$ Federal Communications Commission (Sep. 23, 2005), op cit.

${ }^{15}$ A distinction does remain, however, in that local loops (as are used to deliver voice services) can be leased on regulated terms from incumbent carriers, and these loops can then link customer DSL traffic to digital switches located in the telephone company central office. This form of "open access" is operationally nonbinding, however, in that it is not significantly utilized.

${ }^{16}$ Andrew Jay Schwartzman of the Media Access Project was quoted as saying: "This is a bad day for the Internet. I think it means higher prices and less competition and threatens the growth of the Internet." Northern Light (2005) "FCC Reclassifies DSL as Data Service - Week of 9/20/05," http://www.centerformarketintelligence.com/analystviews/20050920-WeeklyReport.htm

17 The Editors (2006) “Open Net,” The New Republic, June 19, http://www.tnr.com/doc.mhtml?i=20060626\&s=editorial062606

${ }^{18}$ Wayne Rash (2006) “Net Neutrality Advocates Face Off,” eWeek, July 17, http://www.eweek.com/article2/0,1895,1990357,00.asp
} 
yielded by subscriber choices. We, in particular, test whether the U.S. DSL subscriber growth decreases with deregulation after controlling for the concurrent U.S. CM and Canadian DSL and CM penetrations. The main focus is on the effects of the "line sharing" deregulation in 1Q2003, but we also provide an analysis of the 3Q2005 deregulation even though our dataset contains few observations from this second deregulatory period. The pre-deregulation trends are examined as well.

If open access promotes efficiency, the following hypotheses cannot be rejected:

(1) pre-1Q2003: CM unregulated, DSL regulated with line sharing. Prediction: DSL subscriber growth will exceed CM subscriber growth.

(2) 1Q2003-4Q2006: DSL line sharing eliminated in 1Q2003. Prediction: DSL subscriber growth will decline from trend.

(3) 3Q2005-4Q2006: DSL classified “information service” 3Q2005. Prediction: DSL subscriber growth will further decline from trend.

\subsection{Growth of DSL vs. cable modem prior to $1 \mathrm{Q} 2003^{19}$}

While DSL and CM technologies were developed at roughly the same time, unregulated cable companies expanded the availability and penetration of their services more aggressively than regulated telephone companies. By year-end 1999, CM dominated the emerging residential broadband market: residential and small business DSL lines totalled just 0.29 million, while CM subscribers numbered 1.40 million. CM continued its dominance through year-end 2002, when it served 11.34 million, double the number of DSL lines (5.53 million) according to the FCC. See Figure 1.

\footnotetext{
${ }^{19}$ Research on the "broadband race" under this regime has been evaluated in Bittlingmayer \& Hazlett (2002), which is summarized here.
} 


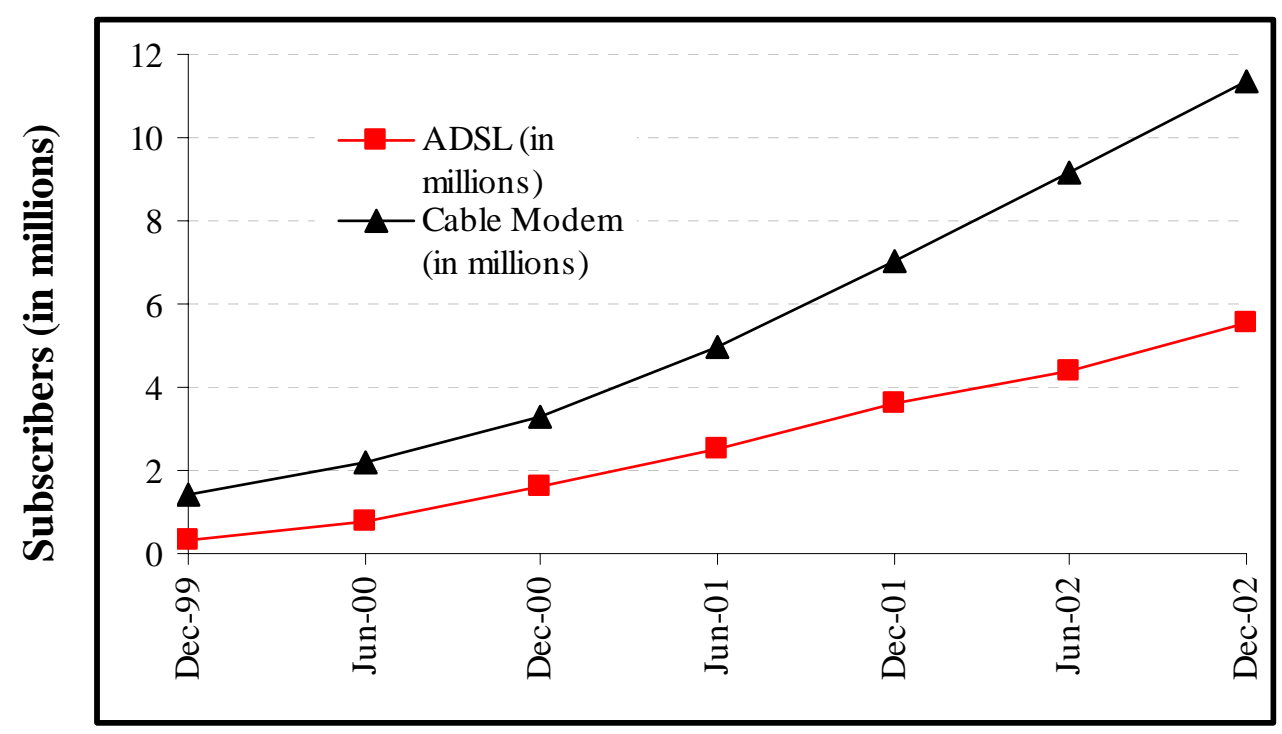

Figure 1: U.S. residential/small business ADSL and cable modem lines, 1999-2002

Source: FCC, High speed services for internet access (semi-annual report).

While factors unrelated to regulation may help explain CM's dominance, these data absent further evidence - are inconsistent with the hypothesis that open access promotes broadband deployment. Moreover, some Wall Street analysts concluded that regulatory factors did play an important causative role in the relatively quick deployment of cable modem services. According to Blake Bath of Lehman Brothers:

The reason that the cable companies really stepped up their investment in 1997 and beyond was they were not regulated, they weren't forced to open up their networks. There were multiple revenue streams that they could address. They could price the services however they wanted. ${ }^{20}$

Investor behavior provides further evidence of the regulatory linkage. In a study of 29 events which, between Jan. 1998 and Oct. 2000, significantly impacted the possibility of “open access" mandates for CM services, Bittlingmayer and Hazlett (2003) found that eight events advancing open access rules produced negative returns for cable modem providers, but no positive returns for the overall Internet Index. ${ }^{21}$ Setbacks for open access were associated with high abnormal (market-adjusted) returns for cable ISPs such as Excite@Home and positive returns for the Internet Index, a portfolio of firms selling Internet-related services. See Table 1. These results are likewise inconsistent with the null.

\section{Internet Index}

\section{Excite@Home}

\footnotetext{
${ }^{20}$ Quoted in Adam Thierer (2001) Transcript from the Cato Institute Policy Forum on July 24, 2001: Broadband and the Markets: Perspectives from the Investment Community, p.15, July 24, http://www.cato.org/events/transcripts/010724et.pdf It is true that wholesale price regulation of DSL networks could spill over to the rival product, depressing CM demand. Yet, to the extent that the network sharing mandates discouraged DSL build-out, upgrades, and marketing investments, and therefore reduced DSL growth, the price controls could boost CM demand. Consistent with this view, industry analysts routinely cited a more favorable regulatory climate for cable operators vs. telephone carriers when assessing broadband markets. See, for example, Jupiter Research (2003) "US Broadband Household Projections: Tier Services and Pricing to Drive Demand,” February 3.

${ }^{21}$ Returns were calculated for 1-day and 3-day periods surrounding open access event announcements. Reported returns are abnormal, Nasdaq-adjusted.
} 


\begin{tabular}{lcccc} 
& 1-day & 3-day & 1-day & 3-day \\
\hline Setbacks for Open Access $(n=21)$ & & & & \\
$\quad$ Mean & 1.1 & 1.7 & 7.6 & 8.1 \\
$\quad$ Median & 0.7 & 2.4 & 8.0 & 8.2 \\
& & & & \\
Victories for Open Access $(n=8)$ & & & & \\
$\quad$ Mean & -0.1 & -0.1 & -4.9 & -6.4 \\
$\quad$ Median & 0.3 & 0.0 & -4.0 & -6.6 \\
\hline
\end{tabular}

Table 1: Abnormal \% returns for internet stock index and Excite@Home around open access events, Jan. 1998-Oct. 2000.

\subsection{DSL growth before 1 Q2003 vs. DSL growth after $1 Q 2003$}

DSL subscribership experienced a sharp increase in trend after the FCC's decision to end line sharing. During this period, DSL subscribership rose from 7.14 million in the first quarter of 2003 to 25.14 million by the fourth quarter of 2006. At the same time, CM subscriber growth continued at a roughly constant linear pace, suggesting the growing DSL penetration was due to factors specific to DSL rather than the broadband market generally. Looking only at CM and DSL, the CM share of residential broadband was 64\% in 1Q2003, with DSL at 36\%. By 4Q2006, CM share had fallen to 54\%, with DSL rising to $46 \%{ }^{22}$

Figure 2 displays DSL and CM subscribership from 1Q1999 through 4Q2006. It includes the linear trend established prior to the line sharing deregulation (extrapolating the 3Q2000 through 1Q2003 trend). By 4Q2006, DSL penetration exceeded this prederegulation forecast by a dramatic 65\%. 4Q20006 CM subscribers, meanwhile, exceeded trend (using the same forecast method) by $11 \%$.

The time series of the residuals from regressing DSL penetration on CM subscribership, 1Q1999 through 4Q2006, illustrates the growth in DSL subscribership. This approach shows that, following deregulation, DSL growth sharply increased relative to the general broadband market as proxied by CM penetration. See Figure 3.

In order to better understand the change in DSL growth after abolition of line sharing in 1Q2003 and to test the hypothesis that “open access” rules for DSL promote efficiency, a simple regression model is constructed,

$$
\ln g_{t}^{U S, D S L}=\beta_{0}+\beta_{1} \ln g_{t}^{U S, C M}+\beta_{2} \ln t+\beta_{3} \text { Switch }_{1}+\varepsilon_{t}{ }^{23} \text { (1) }
$$

which predicts the logarithm of the rate of DSL subscriber growth in period t as a function

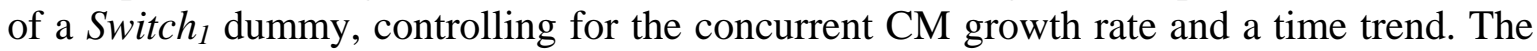
Switch $_{1}$ dummy is set to one for the periods including and after 1Q2003, and zero otherwise. Contemporaneous CM subscriber growth is used as a proxy for general broadband market trends. It is clear that CM penetration is not entirely exogenous, as cable

\footnotetext{
${ }^{22}$ U.S. broadband subscribership data from 1Q1999 through 4Q2006 are collected from two sources. Legg Mason DSL and CM data cover the period from 1Q1999 through 1Q2006. Kagan provides DSL and CM data from 1Q05 through 4Q06. In order to merge the data from different sources, the Kagan data for 2Q2006 and 4Q2006 are normalized with Kagan/Legg Mason multipliers calculated and averaged over the five overlapping data points, 1Q2005-1Q2006.
}

${ }^{23}$ Growth rate of $\mathrm{x}$ in period $\mathrm{t}$ is computed by the formula, $g_{t}^{x}=\frac{s_{t+1}^{x}-s_{t}^{X}}{s_{t}^{X}}$, where $s_{t}^{x}$ is the number of $\mathrm{x}$ subscribers in period $t$. 
TV operators are likely to respond to competitive moves made by DSL providers (and vice versa). However, this endogeneity biases the test in favor of the null, diluting relative DSL growth gains. Table 2 shows the OLS regression results.

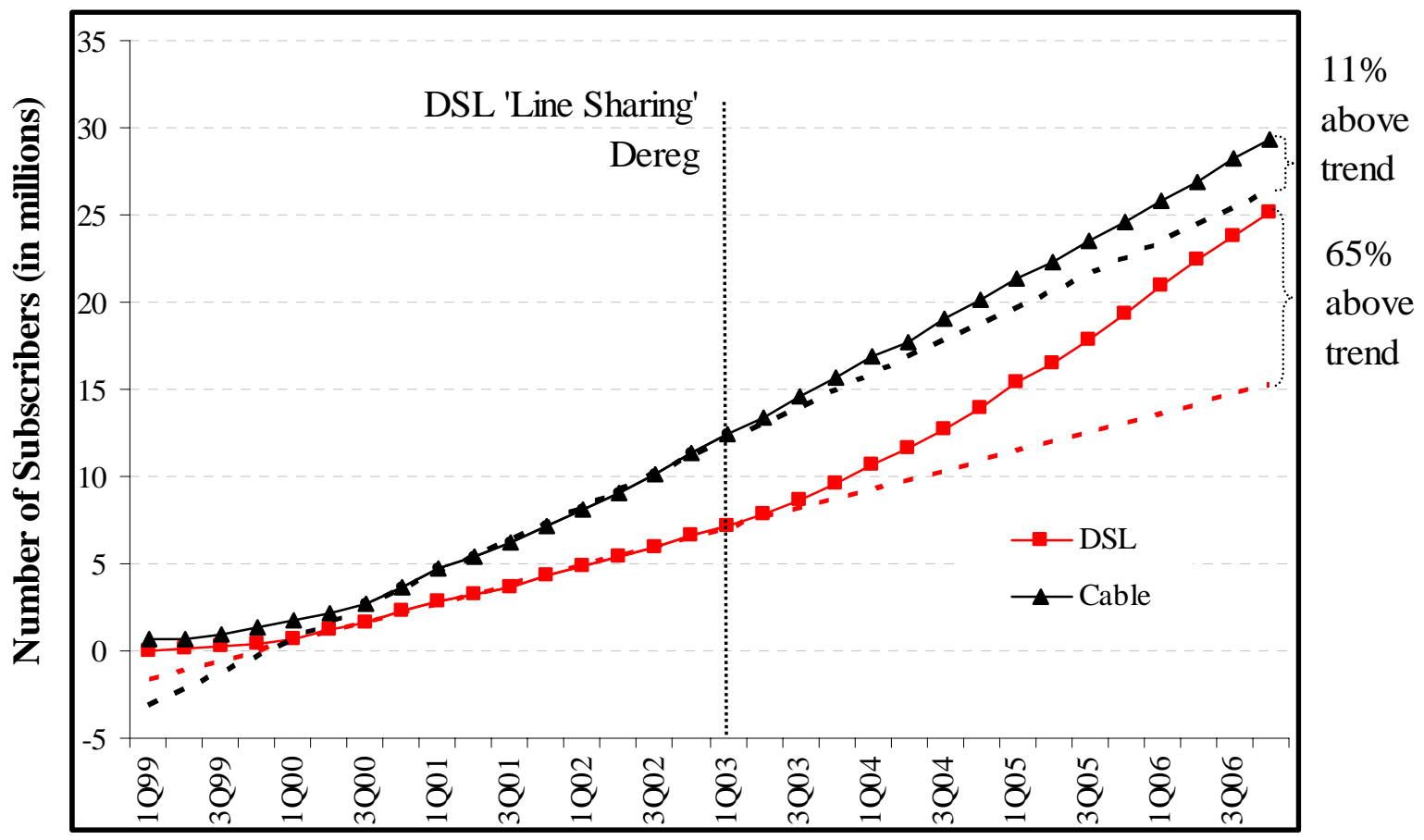

Figure 2: DSL and cable modem subscribers in the U.S., 1Q1999-4Q2006

Note: Projections are linear estimates from 3Q2000-1Q2003. Source: Legg Mason and Kagan.

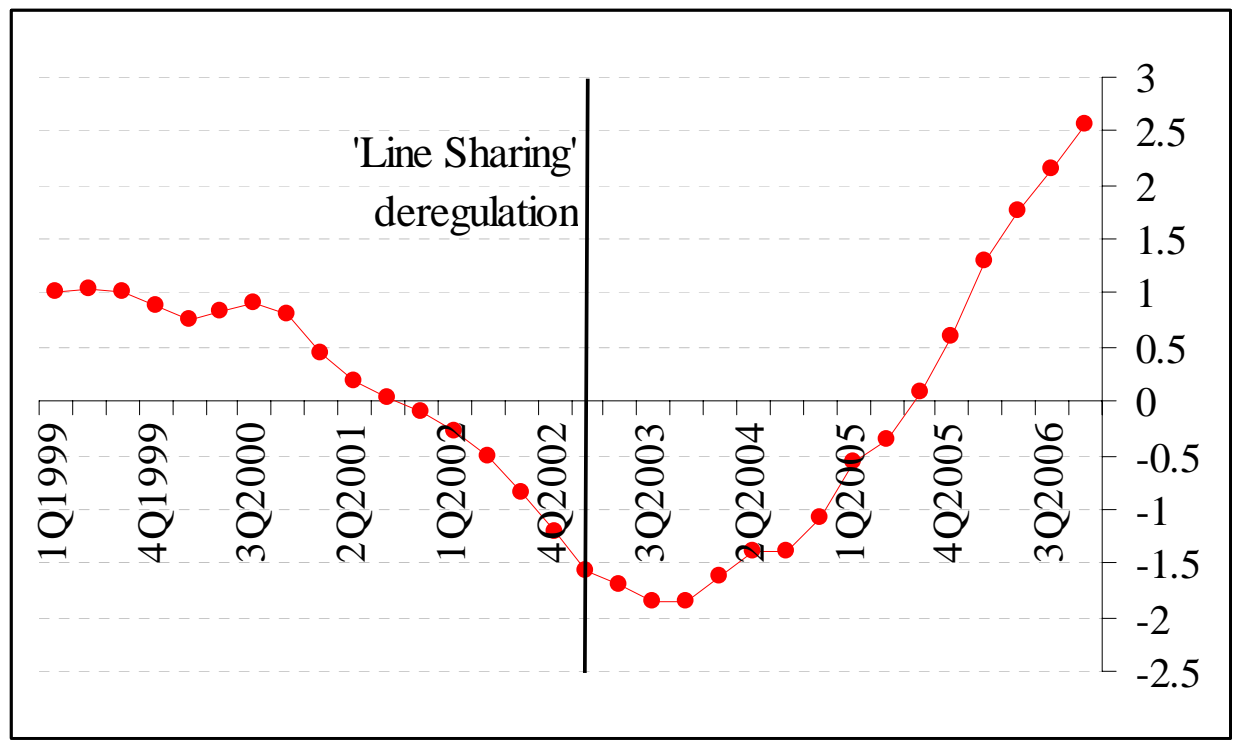

Figure 3: Residual U.S. DSL penetration (x1,000,000), 1Q1999-4Q2006 


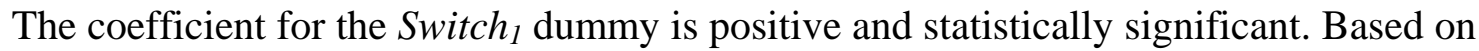
the regression results, the line sharing deregulation is estimated to increase the rate of DSL subscriber growth by $13.3 \%{ }^{24}$

Robustness tests of the OLS regression based on Model 1 indicate a potential firstorder autocorrelation problem. The Breusch-Godfrey LM test, a further test for first-order autocorrelation, obtains a p-value of 0.01 and as a result, the null hypothesis of no serial correlation is rejected. The Prais-Winston estimator corrects for the first-order autocorrelation. The results are listed under Model 1' in Table 2. With this transformation, the Durbin-Watson d-statistic improves from 1.08 to 2.03. The coefficient for the Switch $_{1}$ dummy, on the other hand, remains statistically significant and positive, although lower in value. In this model, deregulation seems to have increased the growth rate of DSL subscribership by $8.6 \%$.

One explanation for the estimated effect of the "line sharing" deregulation might be that there were changes in industry economics independent of the regime switch that tipped growth to favor DSL. For that, concurrent evidence from the Canadian broadband market is examined. If factors specific to DSL technology are helping to accelerate DSL deployment, the same trend should be apparent in the Canadian broadband race. Canada is not only geographically proximate to the U.S., it features similar income levels and highly developed telecommunications infrastructure. It is also structured similarly with respect to broadband, where competition is primarily between CM and DSL service.

Figure 4 displays Canadian DSL and CM sub growth and projections based on the 3Q2000-1Q2003 trend. The trend is extrapolated through 1Q2005 since the Canadian broadband data after 1Q2005 are provided by a different source and there is no overlap with which to normalize the post-1Q2005 data. ${ }^{25}$ As seen in the figure, both DSL and CM subscriber levels in 1Q2005 are lower than the (1Q2003) projections. However, the decrease is less for DSL than for cable modem, signaling that industry economics might have turned in favor of DSL in the post-2002 period. We therefore include the Canadian DSL and CM subscribers as control factors when predicting U.S. DSL subscriber growth in Model 2, estimated as:

$$
\ln g_{t}^{U S, D S L}=\beta_{0}+\beta_{1} \ln g_{t}^{U S, C M}+\beta_{2} \ln g_{t}^{\text {Canada } D S L}+\beta_{3} \ln g_{t}^{\text {Canada, } C M}+\beta_{4} \ln t+\beta_{5} \text { Kagan }+\beta_{6} \text { Switch }+\varepsilon{ }_{t} .
$$

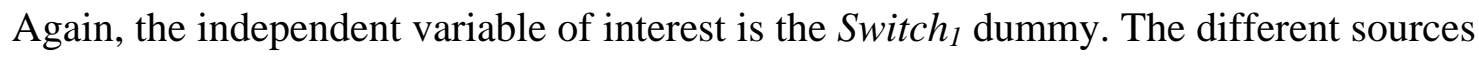
for the Canadian broadband data are also controlled via a dummy, Kagan, set to one for the periods after and including 2Q2005. Results are displayed under Model 2 in Table 2.

The coefficient for the Switch $_{1}$ dummy is positive and statistically significant. The "line sharing" deregulation is estimated to have increased the rate of DSL subscriber growth by $10.2 \%$. The Cook-Weisberg test for heteroskesdasticity performed as a robustness check on the OLS regression for Model 2 leads to a p-value of 0.02. Therefore, the null hypothesis of constant variance can be rejected. However, a subsequent estimation of

\footnotetext{
24 The percentage increase in the rate of DSL subscriber growth when the Switch ${ }_{1}$ dummy takes the value of one is computed by the formula, $100 \beta_{3}^{\prime}=100\left(e^{\beta_{3}}-1\right)$. See Halvorsen and Palmquist (1980).

${ }^{25}$ Canadian broadband subscribership data are, similarly, collected from two sources. Legg Mason DSL and CM data start from 1Q2005 and goes back to 4Q1999. Kagan DSL data extend from 2Q2005 to 4Q2006 whereas Kagan CM data covers the period from 3Q2005 to 4Q2006. The missing CM data point in 2Q2005 is estimated as the average of 1Q2005 and 3Q2005.
} 
Model 2 with robust standard errors indicates that the coefficient for Switch $_{1}$ is still statistically significant. Results are displayed under Model 2' in Table 2.

\begin{tabular}{|c|c|c|c|c|}
\hline & \multicolumn{4}{|c|}{ Dependent Variable: $\ln g_{t}^{U S, D S L}$} \\
\hline & \multicolumn{2}{|c|}{$\begin{array}{l}\text { Entire sample } \\
\text { 1Q1999-4Q2006 }\end{array}$} & \multicolumn{2}{|c|}{$\begin{array}{l}\text { Entire sample including } \\
\text { Canadian broadband data } \\
\text { 4Q1999-4Q2006 }\end{array}$} \\
\hline & 1 & $\mathbf{1}^{\prime}$ & 2 & 2' \\
\hline Constant & $\begin{array}{c}0.84^{*} \\
(0.05)\end{array}$ & $\begin{array}{l}0.84^{*} \\
(0.05)\end{array}$ & $\begin{array}{l}0.91^{*} \\
(0.19)\end{array}$ & $\begin{array}{l}0.91 * \\
(0.33)\end{array}$ \\
\hline $\ln g_{t}^{U S, \text { Cable }}$ & $\begin{array}{l}-0.10 \\
(0.15)\end{array}$ & $\begin{array}{l}-0.14 \\
(0.15)\end{array}$ & $\begin{array}{c}0.00 \\
(0.33)\end{array}$ & $\begin{array}{c}0.00 \\
(0.44)\end{array}$ \\
\hline $\ln t$ & $\begin{array}{l}-0.28 * \\
(0.02)\end{array}$ & $\begin{array}{l}-0.26^{*} \\
(0.02)\end{array}$ & $\begin{array}{l}-0.30 * \\
(0.06)\end{array}$ & $\begin{array}{l}-0.30 * \\
(0.10)\end{array}$ \\
\hline $\ln g_{t}^{\text {Canada,DSL }}$ & & & $\begin{array}{c}0.01 \\
(0.05)\end{array}$ & $\begin{array}{c}0.01 \\
(0.05)\end{array}$ \\
\hline $\ln g_{t}^{\text {Canada,Cable }}$ & & & $\begin{array}{c}-0.30 * * \\
(0.17)\end{array}$ & $\begin{array}{l}-0.30 \\
(0.19)\end{array}$ \\
\hline Kagan & & & $\begin{array}{l}0.06^{*} \\
(0.02)\end{array}$ & $\begin{array}{l}0.06^{*} \\
(0.03)\end{array}$ \\
\hline Switch & $\begin{array}{l}0.12 * \\
(0.03)\end{array}$ & $\begin{array}{l}0.08^{*} \\
(0.04)\end{array}$ & $\begin{array}{l}0.10^{*} \\
(0.03)\end{array}$ & $\begin{array}{l}0.10^{*} \\
(0.03)\end{array}$ \\
\hline $\bar{R}^{2}$ & 0.9482 & 0.9069 & 0.8851 & n.a. \\
\hline $\begin{array}{l}\text { Mean VIF } \\
\text { Shapiro-Wilk }\end{array}$ & 2.66 & n.a. & 7.83 & 7.83 \\
\hline $\begin{array}{l}\text { W test } \\
(p \text {-value=) } \\
\text { Cook- }\end{array}$ & 0.86 & 0.92 & 0.40 & 0.40 \\
\hline $\begin{array}{l}\text { Weisberg test } \\
(p \text {-value }=)\end{array}$ & 0.58 & n.a. & 0.02 & n.a. \\
\hline$D-W$ & 1.08 & 2.03 & 1.72 & 1.72 \\
\hline
\end{tabular}

Table 2: Effects of 1Q2003 "line sharing” deregulation.

Note: Standard errors are in parenthesis. * Significant at the 95\% level. ** Significant at the 90\% level. 


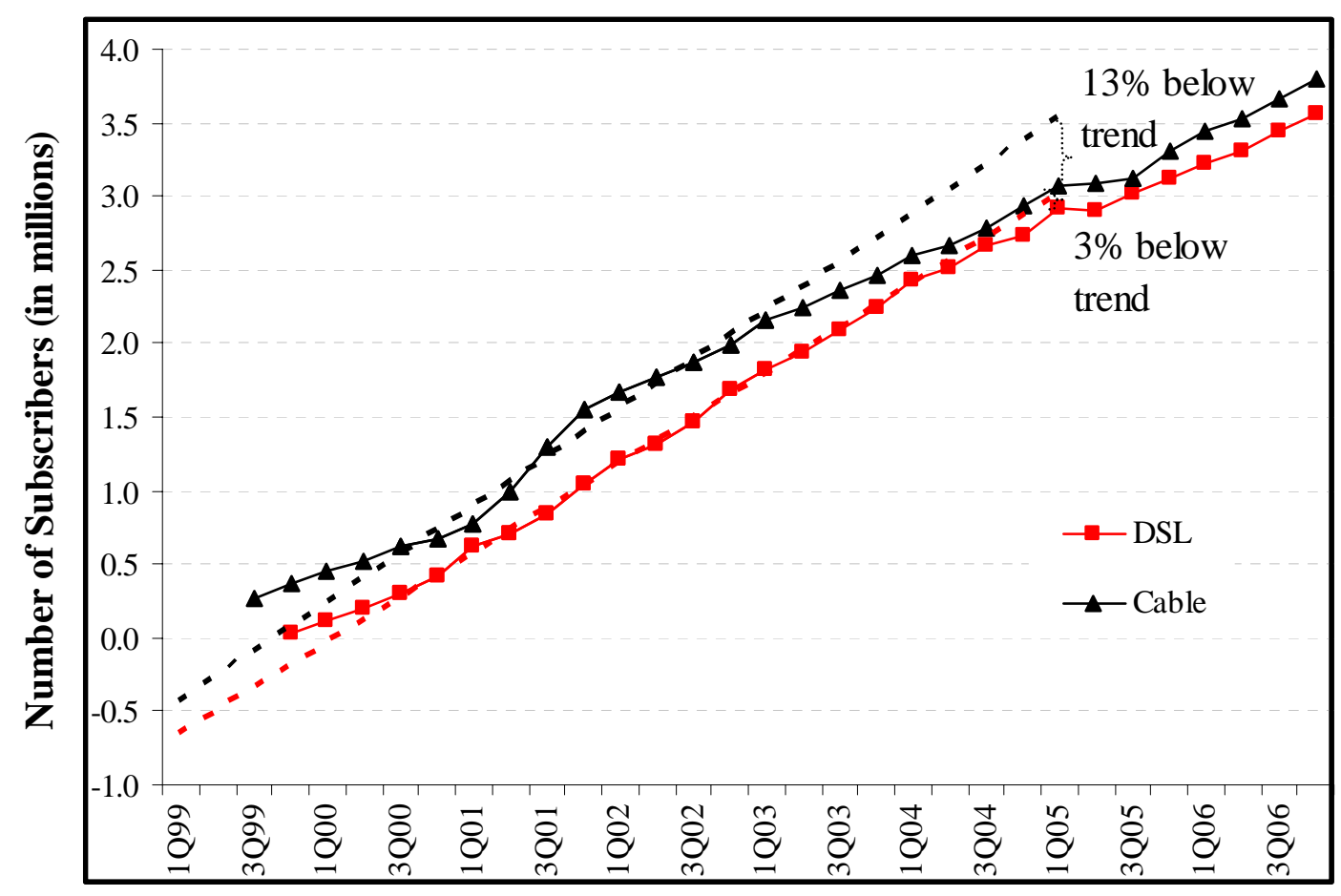

Figure 4: DSL \& cable modem subscribers in Canada, 3Q1999-4Q2006

Note: Projection linearly estimated from 3Q2000-1Q2003. Source: Legg Mason and Kagan.

As an alternative approach, the data are here tested for evidence of a structural break in 1Q2003, following the procedure in Mankiw, Miron, and Weil (1987). The regression model to be estimated,

$$
\ln g_{t}^{U S, D S L}=\beta_{0}+\beta_{1} \ln g_{t}^{U S, C M}+\beta_{2} \ln t+\varepsilon_{t},
$$

is a modified form of Model 1. The Switch ${ }_{1}$ dummy is not included since the model will be estimated for 1Q1999-4Q2002 and 1Q2003-4Q2006 sub-samples separately. These will be the unrestricted regressions to be used in an F test for structural break. The restricted regression is Model 3 estimated using the entire sample, from 1Q1999 through 4Q2006.

An initial OLS estimation of the restricted regression on Model 3 shows, again, a firstorder autocorrelation problem. The Durbin-Watson d-statistic is $0.55 .{ }^{26}$ Therefore, Model 3 is estimated using the Prais-Winston. Table 3 presents the results.

The F statistic for $n_{1}=3$ and $n_{2}=25$ degrees of freedom equals 4.98, which exceeds the critical value of 2.99 (95\% confidence level). The null hypothesis of no structural break in 1Q2003 can be rejected by the data.

Model 4 is the refined form of Model 2, where Canadian broadband data is included. The model,

${ }^{26}$ These regression results are available from the authors. 


$$
\ln g_{t}^{U S, D S L}=\beta_{0}+\beta_{1} \ln g_{t}^{U S, C M}+\beta_{2} \ln g_{t}^{\text {Canada,DSL }}+\beta_{3} \ln g_{t}^{\text {Canada }, C M}+\beta_{4} \ln t+\beta_{5} \text { Kagan }+\varepsilon_{t} \text {, }
$$

is estimated using Prais-Winston to address the first-order autocorrelation problem found in the OLS estimation of the model over the entire sample. ${ }^{27}$ A dummy, Kagan, is used to indicate the use of a different data source, for the dependent variable, for part of the sample. The restricted regression is Model 4 estimated over the entire sample whereas the unrestricted regressions are estimated for 4Q1999-4Q2002 and 1Q2003-4Q2006 subsamples separately. Table 3 shows the results.

The F statistic for $n_{1}=5$ and $n_{2}=17$ degrees of freedom is 3.24 , which exceeds the critical value of 2.81 (95\% confidence level). The null hypothesis of no structural break in 1Q2003 can be rejected after controlling for Canadian broadband trends as well.

As one might suspect, the increase in penetration following the line sharing deregulation in 1Q2003 is accompanied by retail rate reductions. According to Bernstein Research, these price cuts were initiated by SBC in May 2003, with other telcos quickly following (Bernstein Research, 2006). Cable TV operators, while leaving nominal prices relatively stable for cable modem service, responded by aggressively increasing data speeds. ${ }^{28}$ A price series showing estimated U.S. average monthly retail rates for DSL and $\mathrm{CM}$ service is consistent with this explanation. See Figure 5.

\subsection{DSL growth before 3Q2005 vs. DSL growth after 3Q2005}

In August 2005, DSL was further deregulated when the Internet access service was declared by the FCC to be an information service not subject to common carriage regulation. ${ }^{29}$ Figure 6 extends Figure 2, projecting broadband subscriber trends as of 2Q2005 and showing actual levels recorded through 4Q2006.

In Figure 2, a linear time trend ("Trend I") was estimated using actual subscriber data through the first quarter of 2003. ${ }^{30}$ A second linear time trend, shown in Figure 6, is calculated using observed subscriber levels during the intermediate period, 1Q2003 through 2Q2005. This second trend ("Trend II") is then projected through the fourth quarter of 2006. According to this simple method, the increase in DSL households that occurs following the Aug. 2005 DSL deregulation amounts to about $12 \%$ of total projected 4Q2006 subscribers. In other words, DSL subscribership again increases from trend in the period following the 2005 deregulation. Despite the short time for post-reform effects to develop (just six quarters, 3Q2005 to 4Q2006, inclusive), there are about 2.63 million additional households subscribing to DSL by the end of 2006 than if the trend prior to the 2005 deregulation (1Q2003 through 2Q2005) had continued. CM growth, in contrast, is just one percent above the Trend II prediction at year-end 2006.

\section{Dependent Variable: $\ln g_{t}^{U S, D S L}$}

\footnotetext{
${ }^{27}$ Again the OLS regression results are available from the authors upon request.

${ }^{28}$ Bernstein Research (2006) "Broadband Update: Seasonality Remains a Question But Growth Continues Unabated; The Fight Turns to Net Additions,” July 7.

${ }^{29}$ This was an important regulatory step in that ILECs' high-speed data network facilities were categorically removed from access obligations. This solidified carrier property rights, although third party DSL suppliers had already been dealt a lethal blow with the end of line-sharing.

${ }^{30}$ This estimation used ordinary least squares, as do subsequent time trend projections.
} 


\begin{tabular}{|c|c|c|c|c|c|}
\hline \multicolumn{2}{|c|}{$\begin{array}{l}\text { Entire sample } \\
\text { 1Q1999-4Q2006 }\end{array}$} & \multicolumn{2}{|c|}{$\begin{array}{l}\text { pre- "line sharing" } \\
\text { deregulation } \\
\text { 1Q1999-4Q2002 }\end{array}$} & \multicolumn{2}{|c|}{$\begin{array}{l}\text { post-“line sharing” } \\
\text { deregulation } \\
\text { 1Q2003-4Q2006 }\end{array}$} \\
\hline $\begin{array}{l}3 \\
\text { (restricted) }\end{array}$ & $\begin{array}{l}4 \\
\text { (restricted) }\end{array}$ & $\begin{array}{l}3 \\
\text { (unrestricted) }\end{array}$ & $\begin{array}{l}4 \\
\text { (unrestricted) }\end{array}$ & $\begin{array}{l}3 \\
\text { (unrestricted) }\end{array}$ & $\begin{array}{l}4 \\
\text { (unrestricted) }\end{array}$ \\
\hline
\end{tabular}

\begin{tabular}{|c|c|c|c|c|c|c|}
\hline Constant & $\begin{array}{l}0.84 * \\
(0.07)\end{array}$ & $\begin{array}{l}0.97 * \\
(0.26)\end{array}$ & $\begin{array}{l}0.86^{*} \\
(0.05)\end{array}$ & $\begin{array}{l}1.33 * \\
(0.23)\end{array}$ & $\begin{array}{c}0.05 \\
(0.11)\end{array}$ & $\begin{array}{c}0.04 \\
(0.15)\end{array}$ \\
\hline $\ln g_{t}^{U S, C M}$ & $\begin{array}{l}-0.17 \\
(0.15)\end{array}$ & $\begin{array}{c}0.42 \\
(0.30)\end{array}$ & $\begin{array}{l}-0.08 \\
(0.17)\end{array}$ & $\begin{array}{l}-0.44 \\
(0.35)\end{array}$ & $\begin{array}{l}0.93 * \\
(0.36)\end{array}$ & $\begin{array}{c}0.37 \\
(0.46)\end{array}$ \\
\hline $\ln t$ & $\begin{array}{l}-0.24^{*} \\
(0.02)\end{array}$ & $\begin{array}{l}-0.29 * \\
(0.08)\end{array}$ & $\begin{array}{l}-0.29 * \\
(0.02)\end{array}$ & $\begin{array}{l}-0.43^{*} \\
(0.07)\end{array}$ & $\begin{array}{l}-0.01 \\
(0.03)\end{array}$ & $\begin{array}{c}0.00 \\
(0.05)\end{array}$ \\
\hline $\ln g_{t}^{\text {Canada,DSL }}$ & & $\begin{array}{l}-0.12 * \\
(0.04)\end{array}$ & & $\begin{array}{l}-0.03 \\
(0.05)\end{array}$ & & $\begin{array}{c}0.31 \\
(0.24)\end{array}$ \\
\hline $\ln g_{t}^{\text {Canada,CM }}$ & & $\begin{array}{l}-0.19 \\
(0.18)\end{array}$ & & $\begin{array}{l}-0.56^{*} \\
(0.19)\end{array}$ & & $\begin{array}{c}0.06 \\
(0.18)\end{array}$ \\
\hline Kagan & & $\begin{array}{l}-0.03 \\
(0.03)\end{array}$ & & & & $\begin{array}{l}-0.01 \\
(0.02)\end{array}$ \\
\hline $\bar{R}^{2}$ & 0.8356 & 0.4369 & 0.9484 & 0.9243 & 0.5845 & 0.6017 \\
\hline$R S S$ & 0.0441 & 0.0236 & 0.0261 & 0.0112 & 0.0015 & 0.0009 \\
\hline$d F$ & 28 & 22 & 13 & 8 & 12 & 9 \\
\hline $\begin{array}{l}\text { Mean VIF } \\
\text { Shapiro- }\end{array}$ & n.a. & n.a. & n.a. & n.a. & n.a. & n.a. \\
\hline $\begin{array}{l}\text { Wilk W test } \\
\text { (p-value=) } \\
\text { Cook- }\end{array}$ & 0.08 & 0.13 & 0.91 & 0.26 & 0.21 & 0.44 \\
\hline $\begin{array}{l}\text { Weisberg } \\
\text { test } \\
(p \text {-value }=)\end{array}$ & n.a. & n.a. & n.a. & n.a. & n.a. & n.a. \\
\hline$D-W$ & 2.20 & 1.46 & 1.87 & 1.89 & 1.67 & 1.69 \\
\hline
\end{tabular}

Table 3: Test for a structural break in 1Q2003 after "line sharing” deregulation

Note: Pre-"line sharing” deregulation sample for Model 4 goes back to 4Q1999 due to unavailability of the Canadian broadband data. Standards errors are in parenthesis. * Significant at the 95\% level. ** Significant at the $90 \%$ level. 


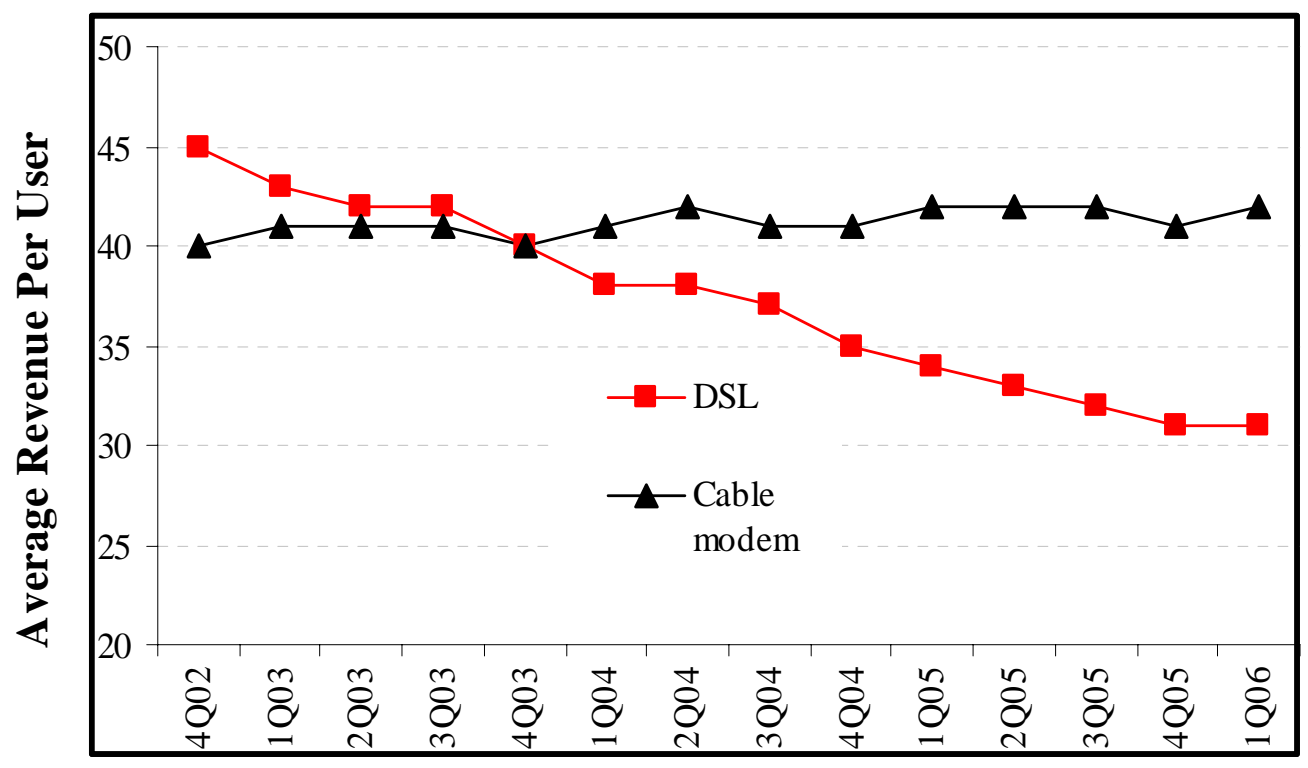

Figure 5: Mean monthly rates for DSL \& CM service, 4Q2002-1Q2006

Source: Bernstein Research (2006) "Broadband Update: Seasonality Remains a Question But Growth Continues Unabated; The Fight Turns to Net Additions,” July.

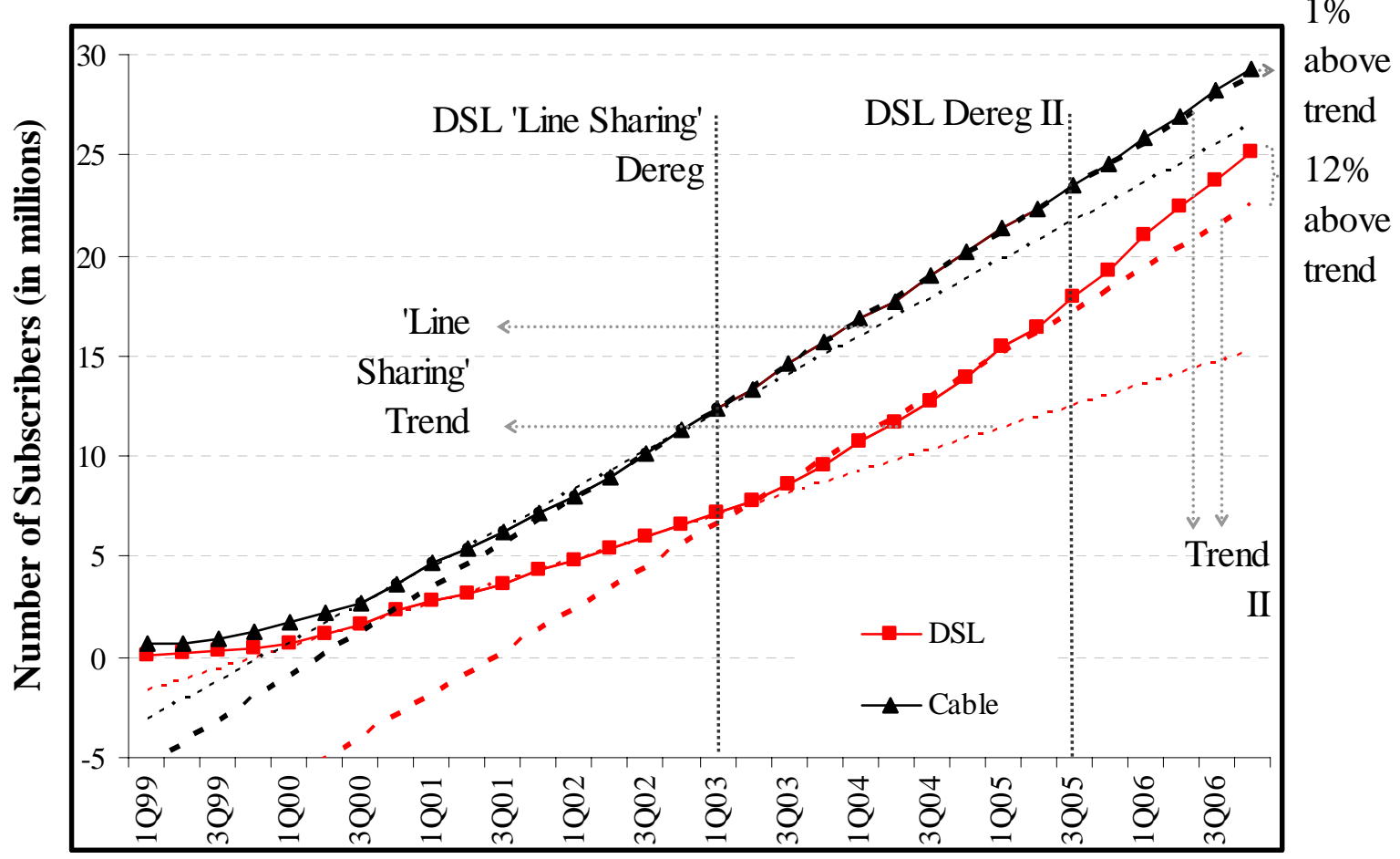

Figure 6: DSL \& CM subscribers in the U.S., 1Q1999-4Q2006

Note: Trend I from 3Q2000-1Q2003; Trend II from 1Q2003-2Q2005. Source: See Figure 2.

To estimate the effects of the August 2005 deregulation on the rate of DSL subscriber, Model I is refined to include a second dummy, Switch 2 , that is set equal to one for the 
periods including and after 3Q2005, zero otherwise. Switch ${ }_{1}$, as before, represents the regulatory switch in 1Q2003. The estimated model is:

$$
\ln g_{t}^{U S, D S L}=\beta_{0}+\beta_{1} \ln g_{t}^{U S, \text { Cable }}+\beta_{2} \ln t+\beta_{3} \text { Switch }_{1}+\beta_{4} \text { Switch }_{2}+\varepsilon_{t} .
$$

Controlling for the logarithm of the rate of concurrent CM growth and time trend as before, the logarithm of the rate of DSL subscriber growth is regressed on two regulatory switch dummies using OLS. The estimated coefficients, contained in Table 4, show that the August-2005 deregulation increased the rate of DSL growth by $6.3 \%$ in addition to the approximately $12 \%$ bump observed following elimination of line sharing.

\begin{tabular}{|c|c|c|c|c|}
\hline & Dependent V & ariable: $\ln g_{t}^{U S, D S L}$ & & \\
\hline & $\begin{array}{l}\text { Entire } \\
\text { sample } \\
\text { 1Q99-4Q06 } \\
5\end{array}$ & $\begin{array}{l}\text { Post-“line sharing” } \\
\text { deregulation } \\
\text { 1Q03-4Q06 } \\
3 \\
\text { (restricted) }\end{array}$ & $\begin{array}{l}\text { Pre-2005 } \\
\text { deregulation } \\
\text { 1Q03-2Q05 } \\
3 \\
\text { (unrestricted) }\end{array}$ & $\begin{array}{l}\text { Post-2005 } \\
\text { deregulation } \\
\text { 3Q05-4Q06 } \\
3 \\
\text { (unrestricted) }\end{array}$ \\
\hline Constant & $\begin{array}{l}0.85^{*} \\
(0.04)\end{array}$ & $\begin{array}{c}0.09 \\
(0.12)\end{array}$ & $\begin{array}{l}-0.02 \\
(0.16)\end{array}$ & $\begin{array}{c}0.43 \\
(0.16)\end{array}$ \\
\hline $\ln g_{t}^{U S, C M}$ & $\begin{array}{l}-0.08 \\
(0.13)\end{array}$ & $\begin{array}{l}0.80 * * \\
(0.42)\end{array}$ & $\begin{array}{c}0.86 \\
(0.48)\end{array}$ & $\begin{array}{l}1.68 \\
(0.59)\end{array}$ \\
\hline $\ln t$ & $\begin{array}{l}-0.28^{*} \\
(0.01)\end{array}$ & $\begin{array}{l}-0.02 \\
(0.03)\end{array}$ & $\begin{array}{c}0.02 \\
(0.04)\end{array}$ & $\begin{array}{l}-0.13 \\
(0.05)\end{array}$ \\
\hline Switch $_{1}$ & $\begin{array}{l}0.11^{*} \\
(0.02)\end{array}$ & & & \\
\hline Switch $_{2}$ & $\begin{array}{l}0.06^{*} \\
(0.02)\end{array}$ & & & \\
\hline $\bar{R}^{2}$ & 0.9587 & 0.5886 & 0.2903 & 0.8624 \\
\hline RSS & 0.0404 & 0.0015 & 0.0010 & 0.0000 \\
\hline$d F$ & 26 & 12 & 7 & 2 \\
\hline $\begin{array}{l}\text { Mean VIF } \\
\text { Shapiro-Wilk }\end{array}$ & 2.35 & 4.10 & 2.46 & 1.19 \\
\hline $\begin{array}{l}\text { W test } \\
(p \text {-value=) } \\
\text { Cook- }\end{array}$ & 0.46 & 0.61 & 0.75 & 0.45 \\
\hline $\begin{array}{l}\text { Weisberg test } \\
(p \text {-value }=)\end{array}$ & 0.29 & 0.43 & 0.97 & 0.78 \\
\hline$D-W$ & 1.45 & 1.48 & 1.87 & 2.62 \\
\hline
\end{tabular}

Table 4: Effects of August-2005 deregulation.

Note: Standards errors are in parenthesis. * Significant at the 95\% level. ** Significant at the $90 \%$ level. 
Based on the methodology employed in the previous section, Model 3 is next estimated using OLS for two sample periods, 1Q2003-2Q2005 and 3Q2005-4Q2006, to test whether a structural break occurs in 3Q2005. These two regressions provide the unrestricted estimates. The restricted regression is Model 3 estimated for the post-"line sharing" deregulation sample, 1Q2003-4Q2006. Results are displayed in Table 4.

The F statistic for $n_{1}=3$ and $n_{2}=9$ degrees of freedom is 1.50, which fails to exceed the critical value of 3.86 (95\% confidence level). Therefore, the null hypothesis of no structural break in 3Q2005 cannot be rejected. This yields no evidence that deregulation slowed broadband deployment, as increases in DSL growth are observed. It does suggest, however, that the incremental effect of the 2005 regime change was not sufficiently large to be distinguishable from random noise.

\section{Summary}

The evidence in U.S. broadband markets suggests that efficiency gains from deregulation. Cable modem services held nearly a two-to-one market share advantage when DSL carriers were most heavily obligated to provide "open access" to competing ISPs. Once the FCC eliminated a key provision of that access regime, ending line sharing in a Feburary 2003 ruling, DSL subscribership increased dramatically. By year-end 2006, DSL subscribership was 65\% higher -more than 9 million households- than it would have been under the linear trend established under "open access" regulation.

DSL growth gains are in evidence even when contemporaneous trends in U.S. cable modem subscribers and Canadian broadband subscribers (both DSL and CM) are controlled for. Moreover, when further DSL deregulation was granted by the FCC as of August 2005, DSL growth did not decline. This robust deployment response is inconsistent with the view that broadband regulation promotes innovation that spurs infrastructure investment or deployment.

Subscriber growth patterns observed across multiple regime switches imply that consumer welfare gains are associated with broadband deregulation. Investment incentives, broadly construed, appear relatively elastic, even in the short run, with respect to network sharing mandates. Given that deregulation of line sharing, the key regime switch examined, was predicted by Prof. Kahn to release only weak incentives for new network infrastructure, the rapid growth of DSL services in the wake of line sharing's repeal presents a strong case for protecting such growth dynamics in public policy.

Further economic research may be able to untangle the microeconomic relations that drive the observed outcomes. The standard explanation relies on efficiencies provided by vertical integration, and encompasses a long list of coordination and incentive issues. Our high-level analysis provides only a perspective on the outcome of the supply and demand changes, and do not reveal the specifics that result in varied deployment levels. Given the richness of the natural experiments provided by regulators, economic organization studies may provide new insights in studying this market.

While net neutrality rules are offered as a substitute for open access regulation, the policies work via different mechanisms. NN regulates access to content by network subscribers, rather than access to physical infrastructure by competing ISPs. Hence, the effects of open access are most informative not for directly establishing that NN rules would stymie network development, but in refuting the reverse claim -that broadband regulation has had no deleterious impact on technology deployment. This argument, 
asserted by NN advocates, is rejected by evidence from the U.S. residential broadband market.

\section{Residential Subscribership}

(in millions)

Actual U.S. DSL, year-end 2006

P1: Projected U.S. DSL, year-end 2006

(extrapolating from the linear trend, 3Q2000-1Q2003)

P2: Projected U.S. DSL, year-end 2006

(extrapolating from the linear trend, 1Q2003-2Q2005)

Actual U.S. CM, year-end 2006

P1: Projected U.S. CM

(extrapolating from the linear trend, 3Q2000-1Q200)

P2: Projected U.S. CM

(extrapolating from the linear trend, 3Q2000-1Q2003)

\section{Actual Canada DSL, 1Q2005}

P1: Projected Canada DSL

(extrapolating from the linear trend, 3Q2000-1Q2003)

\section{Actual Canada CM, 1 Q2005}

P1: Projected Canada CM (extrapolating from the linear trend, 3Q2000-1Q2003)
25.14

(65\% increase from P1, $12 \%$ increase from $P 2$ )

15.25

29.33

(11\% increase from P1, $1 \%$ increase from $P 2$ )

26.41

28.97

2.92

(3\% decrease from P1)

3.02

3.07

(13\% decrease from P1)

3.54

Estimated Increase in Quarterly U.S. DSL Subscriber

Growth from 1Q2003 "line sharing" deregulation

Model 1 - OLS $13.29 \%$

Model 1' - Prais Winston

$8.62 \%$

Model 2 - OLS, controlling for Canadian broadband trends

$10.21 \%$

Model 5 - OLS, controlling for August 2005 deregulation

$12.00 \%$

Estimated Increase in Quarterly U.S. DSL Subscriber

Growth from August 2005 deregulation

Model $5 \quad 6.33 \%$

Table 5: Actual vs. predicted U.S. DSL penetration by 4Q2006.

\section{$5 \quad$ References}

Bernstein Research (2006) "Broadband Update: Seasonality Remains a Question But Growth Continues Unabated; The Fight Turns to Net Additions,” July 7.

Brand X (2005) National Cable \& Telecommunications Assn. v. Brand X Internet Services, 545 U. S. 967. 
Bittlingmayer, George, and Thomas W. Hazlett (2002) "Financial Effects of Broadband Regulation," in Robert Crandall and James Alleman (ed.), Broadband: Should We Regulate High-Speed Internet Access? AEI-Brookings Joint Center for Regulatory Studies: Washington, D.C.

Crandall, Robert W. (2005) Competition and Chaos: U.S. Telecommunications Since the 1996 Telecom Act. Brookings Institution Press: Washington, D.C.

Economides, Nicolas (2007) “'Net Neutrality’, Non-Discrimination and Digital Distribution of Content Through the Internet,” NET Institute Working Paper No. 07-03, May.

Esbin, Barbara (1998) "Internet Over Cable: Defining the Future in Terms of the Past," Federal Communications Commission, OPP Working Paper No. 30, August.

Esbin, Barbara (2000) The Push for Open Access to Cable Systems: Be Careful What You Ask For. Dow Lohnes and Albertson: Washington, D.C.

Farrell, Joseph, and Philip J. Weiser (2003) "Modularity, Vertical Integration, and Open Access Policies: Towards a Convergence of Antitrust and Regulation in the Internet Age," Harvard Journal of Law \& Technology, 17: 85-134.

Faulhaber, Gerald R. (2002) "Broadband Deployment: Is Policy in the Way?” in Robert Crandall and James Alleman (ed.), Broadband: Should We Regulate High-Speed Internet Access? AEI-Brookings Joint Center for Regulatory Studies: Washington, D.C.

Faulhaber, Gerald R. (2003) "Policy-Induced Competition: The Telecommunications Experiments,” Information Economics \& Policy, 15: 73-79.

FCC (1999) In the Matters of Deployment of Wireline Services Offering Advanced Telecommunications Capability and Implementation of Local Competition Provisions of the Telecommunications Act of 1996, Third Report and Order in CC Docket 98-147, December 9,http://www.fcc.gov/Bureaus/Common_Carrier/ Orders/1999/fcc99355.txt

FCC (2005) In the Matter of Appropriate Framework for Broadband Access to the Internet over Wireline Facilities, Report and Order and Notice of Proposed Rulemaking in CC Docket 02-33, September 23.

Halvorsen, Robert and Raymond Palmquist (1980) "The Interpretation of Dummy Variables in Semilogarithmic Equations,” The American Economic Review, 70: 474-75.

Jupiter Research (2003) "US Broadband Household Projections: Tier Services and Pricing to Drive Demand,” February 3.

Kahn, Alfred E. (2003) Lessons from Deregulation: Telecommunications and Airlines after the Crunch. AEI-Brookings Joint Center for Regulatory Studies: Washington, D.C.

Kahn, Alfred E. (2007) “Network Neutrality,” AEI-Brookings Joint Center for Regulatory Studies Related Publication No. 07-05, March. 
Lemley, Mark A., and Lawrence Lessig (2001) "The End of End-to-End: Preserving the Architecture of the Internet in the Broadband Era," UCLA Law Review, 48: 925-972.

Mankiw, N. Gregory, Jeffrey A. Miron and David N. Weil (1987) "The Adjustment of Expectations to a Change in Regime: A Study of the Founding of the Federal Reserve," The American Economic Review, 77: 358-374.

Nuechterlein, Jonathan E. (2008) “Antitrust Oversight of an Antitrust Dispute,” AEI RegMarkets Working Paper No. 08-07, February.

Owen, Bruce M. (2007) “The Net Neutrality Debate: Twenty Five Years After United States v. AT\&T and 120 Years After the Act to Regulate Commerce," Stanford Law and Economics Olin Working Paper No. 336, February.

Owen, Bruce M. and Gregory L. Rosston (2003) "Local Broadband Access: Primum No Nocere or Primum Processi? A Property Rights Approach," Stanford Institute for Economic Research Policy Paper No. 02-037, July.

Peha, Jon (2007) Presentation to the Federal Trade Commission Broadband Connectivity Competition Policy Hearing: Technology and the Benefits and Risks of Network Neutrality Requirements, February $13 . \quad \underline{\text { http://www.ftc.gov/opp/ }}$ workshops/broadband/presentations/peha.pdf

Rosston, Gregory L. (2006) "The Evolution of High-Speed Internet Access 1995-2001,” Stanford Institute for Economic Policy Research Paper No. 05-019, August.

Waverman, Leonard, Meloria Meschi, Benoit Reillier and Kalyan Dasgupta (2007) "Access Regulation and Infrastructure Investment in the Telecommunications Sector: An Empirical Investigation,” LECG, London, September.

Wu, Tim (2003) "Network Neutrality, Broadband Discrimination," Journal of Telecommunications \& High Technology Law, 2: 141-179.

Yoo, Christopher S. (2004) "Would Mandating Broadband Network Neutrality Help or Hurt Competition? A Comment on the End-to-End Debate," Journal of Telecommunications and High Technology Law, 3: 23-68. 